\title{
Treatment of right ventricle to coronary artery connections in infants with pulmonary atresia and intact ventricular septum
}

\author{
John E. Foker, MD, PhD, ${ }^{a}$ Shaun P. Setty, MD, James Berry, RDMS, ${ }^{c}$ Prachi Jain, BS, ${ }^{a}$ Kirsti Catton, RNFA, ${ }^{a, c}$
} Adriana C. Gittenberger-de-Groot, PhD, ${ }^{d}$ and Lee A. Pyles, $\mathrm{MD}^{\mathrm{C}}$

From the Division of Cardiothoracic Surgery ${ }^{\mathrm{a}}$ University of Minnesota, Minneapolis, Minnesota; and Department of Cardiothoracic Surgery, ${ }^{\mathrm{c}}$ The Ochsner Clinic, New Orleans, Louisiana; and the Division of Pediatric Cardiology, ${ }^{\mathrm{b}}$ University of Minnesota, Minneapolis, Minnesota; Department of Anatomy and Embryology, Leiden University Medical Center, ${ }^{\mathrm{d}}$ Leiden, The Netherlands.

Presented in part at the Western Thoracic Surgical Association Meeting (2007) June 27 to 30, 2007, Santa Ana Pueblo, New Mexico.

Supported in part by the Robert and Sharon Kaster Endowment for Pediatric Cardiovascular Surgical Research.

Received for publication July 2, 2007; revisions received Feb 25, 2008; accepted for publication March 30, 2008.

Address for reprints: John E. Foker, MD $\mathrm{PhD}$, Robert and Sharon Kaster Professor of Surgery, Division of Cardiac Surgery, University of Minnesota, 420 Delaware Street SE, MMC 495, Minneapolis, MN 55455 (E-mail: foker001@umn.edu).

J Thorac Cardiovasc Surg 2008;136:749-56 $0022-5223 / \$ 34.00$

Copyright $\odot 2008$ by The American Association for Thoracic Surgery

doi:10.1016/j.jtcvs.2008.03.067
Objective: At the severe end of the spectrum of infants with pulmonary atresia and intact ventricular septum, the likelihood of significant right ventricle to coronary artery connections increases. Our purpose is to present the first series of right ventricle to coronary artery connections ligated off bypass before right ventricular decompression and to evaluate the consequences of this approach.

Methods: From 1988 to 2007, 19 patients with pulmonary atresia and intact ventricular septum had a total of 69 right ventricle to coronary artery connections identified preoperatively, and 10 more were located intraoperatively. Of these, 71 were judged large enough to warrant off-pump direct ligation. Preoperative diagnosis was by transthoracic echocardiography and angiography. Transesophageal and surface echocardiography were used for intraoperative location. Direct visualization and echocardiographic assessment for regional wall motion abnormalities determined the effects of ligation. Right ventricular decompression was done in all patients.

Results: After ligation, coronary flow converted from moderately or largely retrograde to antegrade pefusion. Ligation produced no visual myocardial consequences or immediate local wall motion abnormalities. For 3 patients, however, apical-septal wall motion abnormalities appeared from 2 hours to 3 days postoperatively. Serial studies were done to assess the later effects in the 16 of 19 30-day survivors. No evidence for myocardial injury was found, and all continued on a 2-ventricle repair course.

Conclusion: The location and ligation of right ventricle to coronary artery connections can be reliably accomplished off bypass. Coronary flow became antegrade, improving myocardial oxygenation. No myocardial damage was observed. Inapparent right ventricle to coronary artery connections occasionally enlarge secondarily after right ventricular decompression, making early follow-up evaluation necessary after ligation. Despite the initial presence of significant right ventricle to coronary artery connections, 2-ventricle repairs are possible with long-term benefits.

$\mathrm{T}$ The cardiac lesions found in infants with pulmonary atresia and intact ventricular septum (PAIVS) comprise a wide spectrum of severity. ${ }^{1,2}$ The continuing high mortality rate and frequent palliative repairs documented by consecutive multicenter studies reflect the difficulties posed by these patients. ${ }^{3,4}$ At the severe end of the spectrum, there is increasing hypoplasia of the right ventricles (RVs) and tricuspid valves (TVs), and significant right ventricle to coronary artery connections (RVCACs) may be present. These communications are found in $30 \%$ to $60 \%$ of infants with PAIVS and clearly add to the complexity of treatment. ${ }^{5}$

The operative approach for these infants, even without RV-CACs, has not been settled. Anatomic criteria, such as the degree of TV or RV hypoplasia or whether or not an $\mathrm{RV}$ infundibulum is present, have been used to assign the infants to single-ventricle repair (SVR) or 2-ventricle repair (2VR) tracks. ${ }^{2,4,6,7}$ A 2 VR requires decompression 


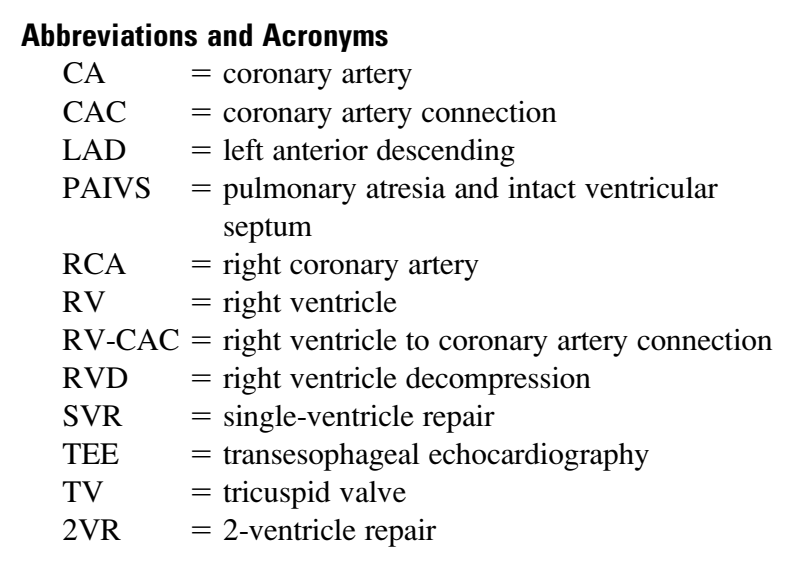

of the RV, which could result in a significant or even fatal myocardial steal if significant communications are present. A palliative SVR has been recommended when large RVCACs with proximal stenoses are found..$^{5,8,9}$

Even if an SVR is the final destination, the continuing presence of significant RV-CACs might be detrimental. Retrograde, high-pressure hypoxic perfusion will exist to some degree, and the observed endothelial lesions and myocardial injury might progress. ${ }^{10,11}$ To limit these detrimental effects and increase $2 \mathrm{VRs}$, we began ligating the RV-CACs off bypass. ${ }^{12}$ Transesophageal echocardiography (TEE) was used to look for signs of ischemia, principally of wall motion abnormalities (WMAs). The purpose of this study was to present the first series of RV-CAC ligations in infants with PAIVS and to define the success and efficacy of this approach.

\section{Materials and Methods \\ Patient Populations}

This is a retrospective analysis of 19 patients (from 1988 to 2007) with PAIVS who had RV-CACs identified and ligated. All patients who had communications judged large enough to warrant ligation and had evidence for 1 coronary artery (CA) communicating with the aorta were included in this series. The 19 patients were $51 \%$ of the 37 patients seen during this time, and only 2 patients with significant CACs but no continuity with the aorta were excluded. The ages and weights at operation are recorded in Table 1.

We have also begun a longer term follow-up of patients with PAIVS who have undergone a 2VR to assess the growth potential of these hypoplastic right hearts. From 1988 to 1999,10 patients who had a small $(z$ score $\leq-4.0)$ TV at initial repair underwent a 5- to 10-year follow-up evaluation of TV size.

\section{Preoperative Evaluation of Right Ventricle to Coronary Artery Connections}

Initial evaluation was by transthoracic echocardiography and angiography. The preoperative studies guided the operative location of the RV-CACs (Figure 1). Additional communications were found intraoperatively by both TE and surface echocardiography (using a $15-\mathrm{MHz}$ linear array) studies.

These diagnostic studies were reviewed, as were the subsequent intraoperative and postoperative echocardiographic and angiogram evaluations. These data reviews were done under institutional review board approval.

\section{Preoperative Right Ventricle and Tricuspid Valve Evaluation}

The preoperative evaluation also included assessing the degree of hypoplasia of the RVs and TVs. From these measurements, the standard deviation of the mean from expected (z score) was calculated on the basis of standard equations and nomograms. ${ }^{2,3}$ The $z$ score has allowed valid comparisons to be made.

The RV end-diastolic volumes were calculated using the biplane method from apical 4-chamber and subcostal views. A 4-chamber view alone results in lower volume estimates. ${ }^{13}$ The biplane method produced distinctly larger estimated volumes, making the $z$ scores higher. The RV volumes were taken at the presumed endocardial surfaces; however, much of the cavitary volume was taken up by large papillary and trabeculated muscle. ${ }^{5}$

The hypoplastic TVs were round rather than elliptical, and the diameter provided the basis for the $z$ score. ${ }^{2,3,4,13}$ We attempted to accurately define the annulus, but the small diameters introduced a significant measurement error.

\section{Surgical Technique and Operative Approach}

The technique used for ligation of the CACs began with the visual inspection of the CAs. The precise location for most connections was revealed by 2 visual clues (Figure 2). Often a rounded protuberance arises from the lateral aspect of the artery. Because the CACs course downward to the RV cavity, this was all that was discernable. A second clue was a decrease in diameter of the epicardial artery, which suggested a branch point and the presence of a CAC diving into the myocardium. Confirmation of the location of the CACs was accomplished by gentle pressure together with TEE observation. For some, there were no clues, and surface echocardiography (by $15-\mathrm{MHz}$ linear array) established the location.

The ligation was carried out by making a small nick in the epicardium on each side of the CAC site, which allowed a 6-0 or 7-0 Prolene suture to be backed around it to the other side of the CA. Tightening a single throw allowed the effects of CAC closure to be determined. If no epicardial changes were seen and no WMAs were observed by echocardiography, ligation was completed.

With the significant RV-CACs ligated, the patient was put on cardiopulmonary bypass, and the RV outflow tract was opened by excision of obstructing muscle. An autologous pericardial patch was placed to create an RV outflow tract of approximately $1.5 \mathrm{~cm}$ in diameter and eliminate the gradient. The atrial septal defect was snared to produce a mild restriction (3-4 $\mathrm{mm} \mathrm{Hg}$ measured by TEE) to reduce right-to-left shunting and enhance TV flow. ${ }^{13}$ Two patients without a main pulmonary artery had a polytetrafluoroethylene (Gore-Tex, Gore and Associates Inc, Flagstaff, Ariz) conduit placed to establish continuity between the $\mathrm{RV}$ and the pulmonary artery confluence. Because of small RV 
TABLE 1. Patients who had ligation of right ventricle to coronary artery connections before bypass and placement of a right ventricle outflow tract patch

\begin{tabular}{|c|c|c|c|c|c|c|c|c|c|}
\hline \multirow[b]{2}{*}{ No. } & \multirow[b]{2}{*}{ YOB } & \multirow[b]{2}{*}{ Age (d) } & \multirow[b]{2}{*}{ Weight } & \multirow[b]{2}{*}{ RV Z } & \multirow[b]{2}{*}{ TV Z } & \multicolumn{2}{|c|}{ RV-CACs } & \multirow[b]{2}{*}{ Repair } & \multirow[b]{2}{*}{ Outcome } \\
\hline & & & & & & Preoperative & Ligated & & \\
\hline 1 & 1988 & 191 & 5.8 & -5.3 & -5.4 & 5 & 5 & 2VR & Discharged \\
\hline 2 & 1989 & 16 & 3.4 & -12.4 & -4.1 & 2 & 2 & 2VR & Discharged \\
\hline 3 & 1989 & 67 & 2.0 & -10.2 & -3.1 & 4 & 4 & $2 V R$ & Expired $(98 d)^{a}$ \\
\hline 4 & 1992 & 2 & 3.2 & -3.8 & -4.2 & 2 & 2 & $2 \mathrm{VR}$ & Discharged \\
\hline 5 & 1993 & 1 & 3.4 & -5.0 & -4.7 & 3 & 3 & $2 \mathrm{VR}$ & Discharged $^{\mathrm{b}}$ \\
\hline 6 & 1995 & 8 & 2.1 & -6.3 & -2.9 & 2 & 6 & $2 \mathrm{VR}$ & ECMO, expired $(5 d)^{c}$ \\
\hline 7 & 1996 & 946 & 12.3 & -3.8 & -7.8 & 3 & 4 & $2 \mathrm{VR}$ & Discharged \\
\hline 8 & 1996 & 6 & 3.8 & NA & NA & 1 & 1 & $2 \mathrm{VR}$ & Discharged \\
\hline 9 & 1996 & 32 & 2.1 & -3.6 & -4.1 & 1 & 2 & $2 \mathrm{VR}$ & Discharged \\
\hline 10 & 1998 & 4 & 3.3 & -3.2 & -2.8 & 1 & 2 & $2 \mathrm{VR}$ & Discharged \\
\hline 11 & 1999 & 3 & 3.4 & NA & NA & 2 & 2 & $2 \mathrm{VR}$ & Expired $(5 d)^{d}$ \\
\hline 12 & 2000 & 8 & 2.6 & -4.1 & -4.4 & 7 & 3 & $2 \mathrm{VR}$ & Expired $(91 d)^{e}$ \\
\hline 13 & 2000 & 27 & 2.8 & -6.1 & -5.4 & 4 & 4 & $2 \mathrm{VR}$ & Expired $(1 \mathrm{~d})^{f}$ \\
\hline 14 & 2001 & 8 & 4.7 & -2.5 & -3.1 & 2 & 2 & $2 \mathrm{VR}$ & Discharged \\
\hline 15 & 2003 & 4 & 3.6 & -11.2 & -5.6 & 3 & 3 & $2 \mathrm{VR}$ & Discharged \\
\hline 16 & 2004 & 7 & 2.7 & -3.5 & -12.2 & 6 & 6 & $2 \mathrm{VR}$ & Discharged $^{\mathrm{g}}$ \\
\hline 17 & 2005 & 4 & 3.1 & -7.0 & -4.6 & 6 & 9 & $2 \mathrm{VR}$ & ECMO, discharged ${ }^{\mathrm{h}}$ \\
\hline 18 & 2007 & 26 & 3.6 & -4.7 & -6.3 & 7 & 6 & $2 \mathrm{VR}$ & Discharged \\
\hline \multirow[t]{2}{*}{19} & 2007 & 14 & 3.8 & -7.3 & -7.6 & 8 & 5 & $2 V R$ & Discharged \\
\hline & & & & $-5.9+2.8$ & $-4.8+1.5$ & 69 & 71 & & $14 / 19(74 \%)$ discharged \\
\hline
\end{tabular}

$Y O B$, Year of birth; 2VR, 2-ventricle repair; NA, not available; ECMO, extracorporeal membrane oxygenation. Age, weight, and $z$ score of RVs and TVs at time of RV-CAC ligation. The number of connections identified preoperatively and the number ligated are given. 2VR included an RV outflow tract patch, often a shunt and reduction in atrial septal defect size. ${ }^{\text {a Very premature infant originally who was ready for discharge and died of large overdose. }{ }^{b} A p i c a l ~ W M A ~ d e v e l o p e d ~} 3$

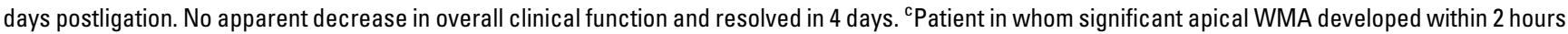
of bypass. Placed on ECMO. Function recovered, and she was to be taken off ECMO when a severe central nervous system bleed was discovered. ${ }^{\text {P } P a t i e n t}$ underwent repair at outside hospital. Also had postcatheter traumatic RV aneurysm and depressed function at time of repair. Low output continued without reversal. ${ }^{e}$ Patient with severe DiGeorge's syndrome died of candida sepsis. Had LV endocardial fibroelastosis, but cardiac function was good. ${ }^{\mathrm{f} P a t i e n t}$ transferred at 23 days of age with intractable arrhythmias, renal failure, and severe edema. Postoperatively, the arrhythmias continued and degenerated to ventricular fibrillation. ${ }^{9}$ Erroneous TV size because of covered TV and mitral valves, which made the openings appear smaller than actual. Not included in TV average. 'Significant apical WMA developed in the patient within 1.5 hours of bypass. Supported by ECMO. Two days later, the patient was returned to the operating room and 2 connections were ligated. Taken off ECMO the next day.

and TV size, 11 patients had an ascending aorta to right pulmonary artery shunt.

\section{Results}

\section{Preoperative Coronary Artery Evaluation}

By angiography, the coronary circulation might appear to be fed entirely from the RV when coupled with a root aortogram that did not show the CAs (Figure 1). Because the RVs typically had suprasystemic pressures, the CAs were often best visualized by the retrograde flow through the RV-CACs. Nevertheless, by careful echocardiographic evaluation, some antegrade CA flow could be seen early in diastole, indicating continuity with the aortic root.

Lesions within the CAs were common in infants with significant RV-CACs; therefore, the angiograms were assessed for stenoses. Only 6 angiograms, however, were satisfactory for complete evaluation. In these 6 patients, 3 apparent obstructions and 13 stenoses of $25 \%$ to $75 \%$ in the major CAs were found. Consequently, as has been reported, intimal hyperplasia with stenoses was common with significant RV-CACs. ${ }^{10,11}$

True RV dependence requires the absence of aortic communication or at least the presence of significant proximal stenoses of the CAs that would put a large amount of myocardium at risk without retrograde flow. ${ }^{5,8,9}$ We used the short antegrade CA flow as evidence that a proximal connection existed but found that the quantitation of the severity of possible stenoses was imprecise. The retrograde studies were not always satisfactory, and selective coronary angiograms were difficult. In addition, ligation of the connections eliminated the distal steal, which reduced the functional consequences of the stenoses. Because we planned a trial ligation of each RV-CAC off bypass, the adequacy of antegrade flow to make up for the retrograde loss would be quickly apparent.

The diameters of the CAs were variable and ranged from larger than normal because of the connections, to being 

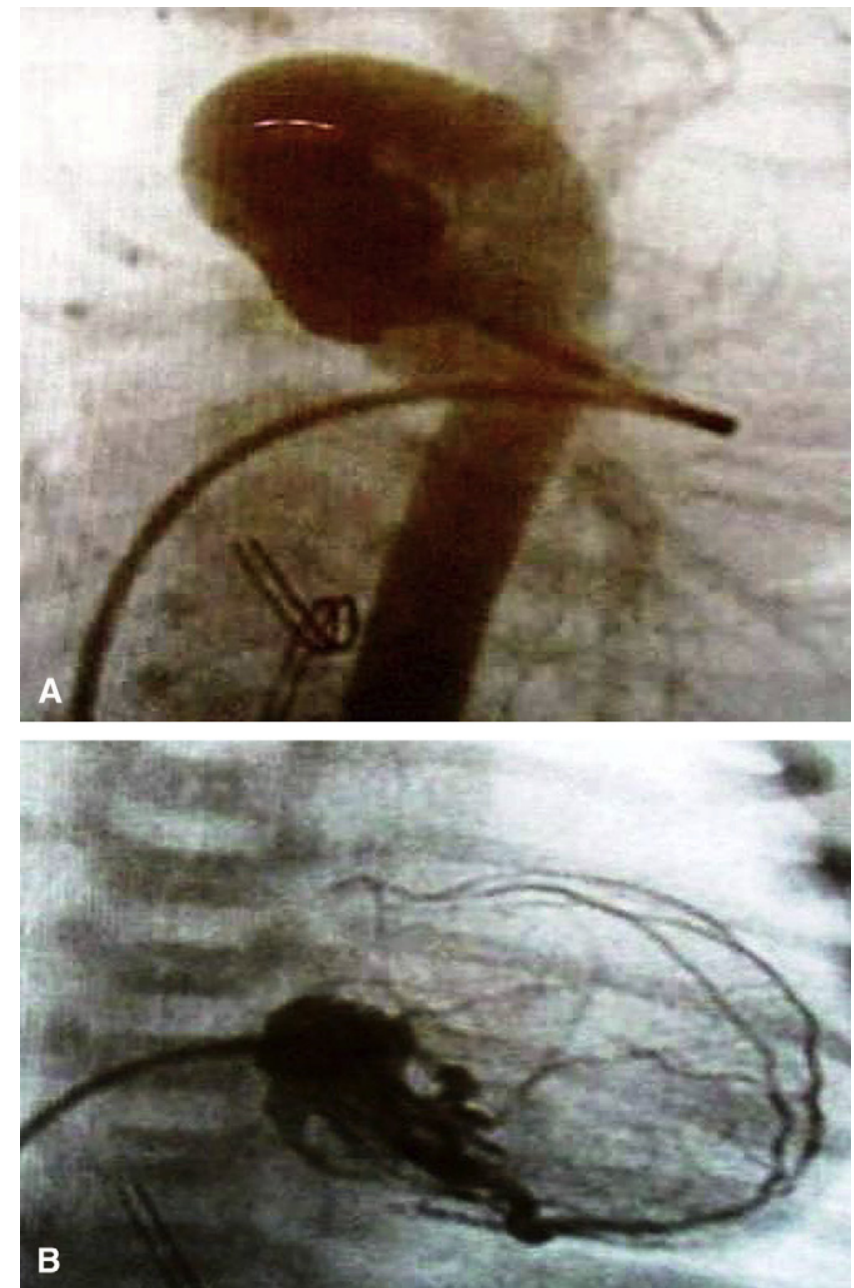

Figure 1. Angiograms showing no apparent CA filling with aortic injection $(A)$ and retrograde filling of coronary system with $R V$ injection (B). Three large and 3 small connections were seen (RV z score -11.1)

narrowed, presumably from intimal hyperplasia. ${ }^{10}$ In 1 patient, even though there was complete proximal left anterior descending (LAD) occlusion, the vessel was so narrowed it was no longer important and ligation of the CAC was without effect.

The diameters of the connections also varied in size and ranged from $3 \mathrm{~mm}$ to less than $0.5 \mathrm{~mm}$. For the smaller connections, the judgment of significance was subjective. Because of the potential for postoperative enlargement, however, all but the smallest were ligated. None of the small CACs left behind subsequently enlarged. Nevertheless, delayed apical-septal WMAs appeared in 3 patients in whom no remaining RV-CACs were suspected (Table 1).

In no instance was there evidence of injury by ligation of a CAC. Consequently, in this series, a problem (from
WMA to decreased output) only occurred with an enlargement of an unsuspected CAC and not with ligation of a known connection.

\section{Preoperative Right Ventricle and Tricuspid Valve Evaluation}

The preoperative RV $z$ scores ranged from -2.5 to -12.4 (average $-5.9 \pm 2.8$ ), and the $\mathrm{TV} z$ scores ranged from -2.8 to -7.8 (average $-4.8 \pm 1.5$ ) (Table 1$)$.

\section{Operative Results}

The 19 patients had a total of 69 RV-CACs identified preoperatively, and the epicardial echocardiography studies located an additional 10 communications. A total of $71 \mathrm{RV}-\mathrm{CACs}$ were ligated epicardially off bypass. Occlusion was verified by echocardiography. Of these, 28 came off the right coronary artery (RCA), 26 came off the LAD, and 17 came off the apex, usually at a confluence of the RCA, LAD, and circumflex arteries. Therefore, 8 were left behind. Follow-up aortograms have not found connections (Figure 3).

As the communications were eliminated for each major arterial branch, the coronary blood flow became increasingly antegrade by transesophageal Doppler echocardiography. Even when preligation antegrade flow was barely discernable, conversion to complete antegrade flow occurred.

Surface changes or local WMAs were not observed in the area of the ligations by direct visualization of the myocardium or TEE assessment. One infant had no proximal connection of the LAD, and 2 infants had apparent obstructions of the RCA. Nevertheless, ligation of the communications produced no WMA.

All patients had resection of the RV outflow tract obstruction along with the excision of additional muscle bundles to reach the RV cavity and eliminate an outflow gradient. Because of the relatively extensive muscle excision, the troponin levels would be expected to be elevated and were not measured. All patients had an RV outflow tract patch of autologous pericardium placed. For 11 of 19 patients $(59 \%)$, a shunt was added.

The 30-day mortality was 3 of 19 patients (16\%), and 14 of 19 patients $(74 \%)$ were discharged (the late deaths were the result of severe immune compromise and an iatrogenic problem). Since 2002, 6 of 6 patients have been discharged (Table 1).

\section{Consequences of Right Ventricle to Coronary Artery Connection Ligation and Right Ventricle Decompression}

Our results demonstrated the unpredictable nature of the communications. In 3 infants $(3 / 19,16 \%)$ with no known CACs left behind, new apical-septal WMAs appeared within hours or days (Table 1). The communications were not apical in location but were higher on either the RCA or LAD. Presumably, the more proximal site of the steal reduced 

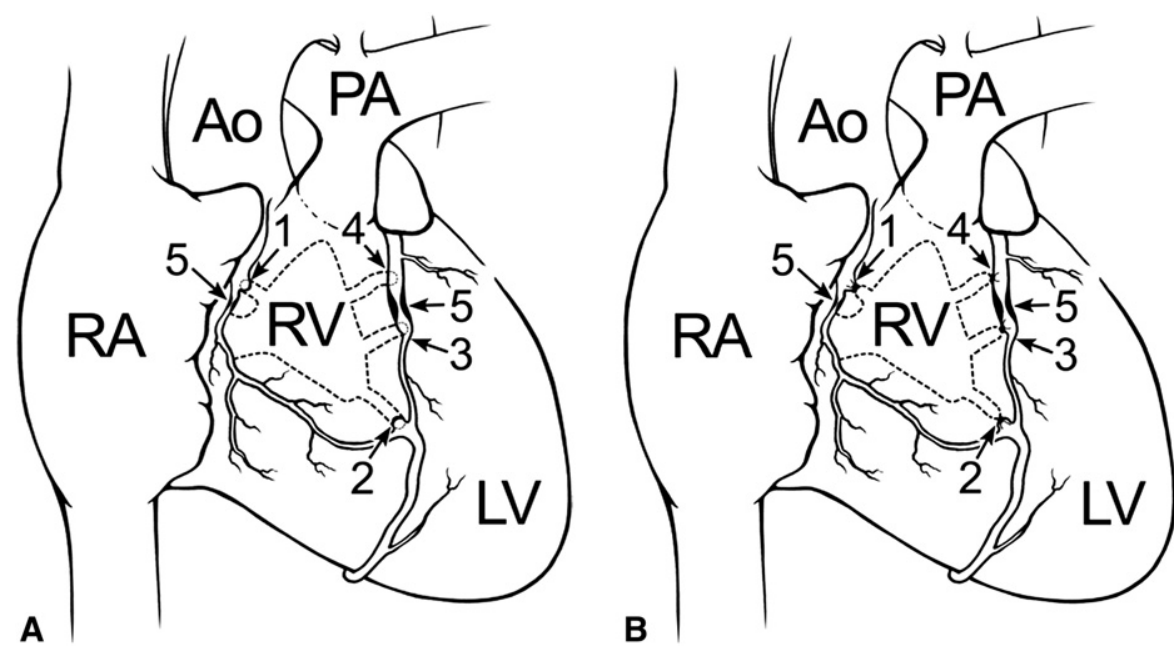

Figure 2. The typically small RV is outlined by the RCA and LAD. Represented are the 3 surface appearances of significant RV-CACs (A). Two (1 and 2) are depicted as lateral protuberances of the CAs, which indicate the presence of a significant CAC that dives to the RV cavity. Another configuration is a relatively abrupt narrowing of the $C A$, in this case the LAD, which suggests the presence of a significant CAC (3). Occasionally, there are no surface clues to the presence of a significant CAC and the location must be determined by surface echocardiography (4). By angiography, narrowing of the arteries unrelated to the CACs may be revealed (5). The companion drawing (B) depicts the CACs ligated just beneath the CAs. Ao, Aorta; $P A$, pulmonary artery; $R A$, radial artery; $R V$, right ventricle; $L V$, left ventricle.

perfusion at the distal end of the coronary arterial tree (the apex). For 1 infant who required extracorporeal membrane oxygenation support, 2 new CACs appeared, as did apicalseptal dysfunction. With ligation of the CACs, extracorporeal membrane oxygenation could be weaned.

We found no evidence of significant CACs appearing later than 3 days after the initial procedure; therefore, we recommend serial echocardiograms in the early postoperative period. In contrast, none of the 8 CACs judged insignificant and left unligated later enlarged and no WMAs appeared in these patients.

\section{Evaluation of Tricuspid Valve Growth}

Ten patients born with TVs had a $z$ score of -4.0 or less and had adequate echocardiography analysis 5 to 10 years after 2VR (4 of these patients are part of this RV-CAC series). The preoperative $z$ score average was $-4.6 \pm 0.4$ and on follow-up was $-0.04 \pm 1.5$. Only 1 early patient (1989) with incomplete relief of RV outflow obstruction and 2 large atrial septal defects, both of which reduce TV flow and, consequently, growth, failed to reach normal TV size. ${ }^{13}$ Even with a TV $z$ score of -3.5 on last follow-up, this patient had a 2 VR.

\section{Discussion}

Pulmonary atresia with an intact ventricular septum is a deceptively simple term for a complex and difficult spectrum of lesions. The recent multi-institutional study again reported a $40 \% 5$-year mortality and found only $33 \%$ of these infants undergo a 2 VR. ${ }^{4}$ In addition, the outcomes of the participating institutions were determined for the 5-year prevalence of end states, including 2VRs, 1.5VRs, and SVRs, as well as death. The wide variation found in treatments and outcomes among the centers was striking. Clearly, the complexity of these infants has, so far, thwarted a uniform approach and similar institutional results.

The variations in treatment and outcomes stem largely from the complexity of the patients with PAIVS. The spectrum of abnormalities found in patients with PAIVS has 3 main components (TV, RV, and CACs), and each has its own spectrum of severity. Although there are correlations among the components related to the degree of hypoplasia, there is not a common progression of severity and considerable variation exists. Also important are the differing judgments about the significance of the lesions themselves and how they affect the potential for successful 2VR and SVRs.

The TV has been considered by many to be the most important factor influencing outcomes. ${ }^{4,14}$ The multi-institutional study found a small TV was a consistent risk factor for death and a SVR. ${ }^{4}$ Predictably, a TV closer to normal in size improved the chances of undergoing a 2VR. Although the presence of RV-CACs and the RV size tend to track with the TV $z$ score, neither was an independent risk factor for death or palliative repairs. The absence of significant RVCACs or an RV size (excluding Ebstein's malformations) closer to normal, however, led more frequently to a $2 \mathrm{VR}$.

There are at least 2 reasons why RV-CACs did not emerge as an independent risk factor for death in the institutional study. Most important would seem to be that, although they cluster with the small TVs, RV-CACs comprise another spectrum of severity within patients with PAIVS. Some communications are small and may involute; therefore, they do not 

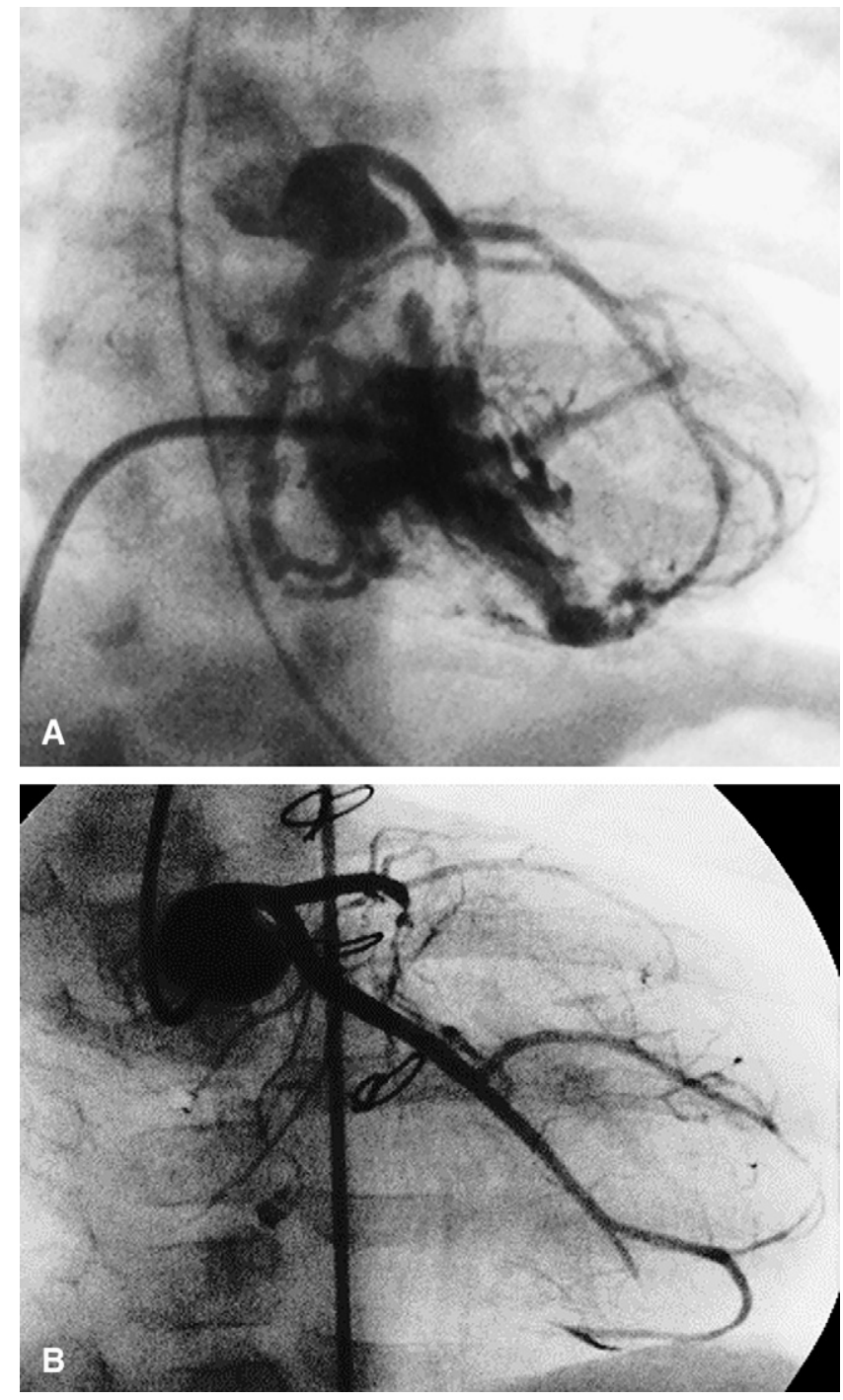

Figure 3. Preoperative filling with RV injection in another patient (A). Seven connections were identified. Postligation follow-up (6 months later) aortogram reveals no remaining connections (B).

pose a consistent threat. In addition, they are found in approximately half of the infants with small TVs, making it difficult for them to emerge as an independent risk factor in pooled multi-institutional results. ${ }^{4}$ Numerous reports, however, as well as our experience, indicate they may be very detrimental in individual cases. ${ }^{5,8}$ Because they are not a primary risk factor for death, our case for ligation of RV-CACs will depend on their early functional consequences and effects on both SVR and 2VR repairs, as well as longer-term outcomes.

Several insightful articles have been published on the developmental events, pathologic consequences, and natural history of RV-CACs. ${ }^{5,10,11,15,16}$ The origin of these commu- nications was determined by Gittenberger-de Groot and colleagues, ${ }^{10,15,16}$ who showed that 1 of 2 abnormal CA developmental scenarios may occur with important pathologic implications. The clinically significant communications in this study are essentially straight-through connections between the RV and CAs, which can be seen by echocardiography and angiogram. These abnormal vessels were judged as the primary embryologic event, with pulmonary atresia developing later.

A second type of vascular link, termed "sinusoids," form after pulmonary atresia. The suprasystemic RV pressures dilate the intratrabecular spaces, which feed into the myocardial capillary bed before communicating with the CAs. ${ }^{10,15,16}$ The suprasystemic RV pressures would not be relieved through the capillaries which protects the endothelium but makes endocardial fibroelastosis more likely, as is found in some patients with PAIVS without apparent connections.

Arterial lesions were found in all patients with RV-CACs in 2 detailed pathologic studies, and often, the changes were severe. ${ }^{10,11}$ Intimal proliferation was extensive, and perivascular fibrosis often was present. As a result, stenoses and even obstructions, as well as lengthy narrowings, were common and presumably resulted from the high pressure retrograde perfusion with hypoxic blood. The usual developmental connection of the CAs with the aorta may not be made in extreme cases, including 2 of our patients. ${ }^{16}$

The vascular lesions likely caused the frequent patches of old and more recent myocardial damage that were seen. Certainly, the surgeon observes that the myocardial surface is typically blotchy in appearance, often with a yellowish hue, suggesting poor perfusion.

The natural history of these communications was addressed by the Boston group in a series of articles that helped define the consequences of RV-CACs. ${ }^{8,17,18}$ To maximize 2VRs, RV decompression (RVD) was carried out in 16 infants with RV-CACs. ${ }^{8}$ No stenoses had been found in the preoperative angiograms in 7 patients, and all survived RVD. A stenosis of $1 \mathrm{CA}$ was found in 6 patients, and 1 patient died with LV dysfunction after RVD, as did all 3 patients with stenoses of both CAs. ${ }^{8}$

Even when the CA abnormalities were "less extensive," there was a functional price for RVD in the presence of RV-CACs. Detailed LV regional analysis was carried out in 12 patients, and the functionally abnormal regions increased from $6 \%$ to $12 \%$ after RVD and 1 patient died with severe LV dysfunction. ${ }^{18}$ For infants with PAIVS without RV-CACs, regional LV dysfunction was rare $(<1 \%)$ after RVD.

Taken together, these studies provided important information on the dynamics of the steal phenomenon. The effects of steal were dependent on the significance of CA lesions present. Because lesions are common in these patients, functional and ischemic consequences were relatively frequent after RVD even for less extensive CA lesions. ${ }^{8,17}$ The 
consequences of a steal were much greater when stenoses limited the antegrade flow and might prove fatal. ${ }^{8}$

Our patients had similar evidence for vascular disease, including obstructions, stenoses, and severe narrowings. In our approach, however, the ligation of the connections eliminated the steal component and only tested the limitation to forward flow after RVD. The functional consequences of the CA lesions may be much less than predicted after RVD with the steal eliminated. Not all RV-CACs can be identified before RVD, however, and a few may appear later.

Without eliminating the steal effect, the presence of significant RV-CACs make a 2VR risky and an SVR track is often recommended. 4,5,6,8,9,19 Several lines of evidence suggest, however, that the longer-term results of SVR may be comprised by some combination of a hypertensive RV and significant RV-CACs. Decompression of the RV leads to better survival in patients with PAIVS even in the absence of RV-CACs. ${ }^{17}$ The presence of significant connections was associated with decreased LV function in newborns with PAIVS and persistent RV hypertension. CA pathology may progress in patients with RV-CACs. ${ }^{8,20}$ Even in patients without PAIVS, RV outflow obstruction decreased LV function. ${ }^{21}$ An increased interim mortality was found in survivors of a shunt as the first stage of an SVR, and 2 of our patients with shunted PAIVS, before this series, died unexpectedly at home. ${ }^{22}$ For patients with PAIVS who underwent a Fontan procedure, LV function was more abnormal than for patients with tricuspid atresia at the same stage. ${ }^{23}$

These findings suggest the ability to take down the RVCACs should be beneficial whatever the final repair. The potential for 2VR repairs is increased with RVD. Even for SVRs, ligation of the RV-CACs should help to maintain better $\mathrm{LV}$ function for the long term and reduce the late attrition of these patients.

Our results have shown that the RV-CACs can be found and reliably interrupted, reversing the predominantly retrograde perfusion to antegrade flow. Taking away the hypertensive, hypoxic coronary blood flow may also remove the stimulus to the well-described CA lesions. ${ }^{10,11}$ At the least, the CAs could begin a normal growth pattern, making the lesions less significant. Of course, the rare occurrence of no adequate communication between the aorta and the CAs is not amenable to this approach, and heart transplantation is necessary.

To maximize the possibility of a 2-ventricle repair, we and others have long advocated an RVD to encourage right heart growth. ${ }^{8,24}$ A patient with RV-CACs, judged preoperatively to be unimportant, however, underwent an RVD, and during several hours, myocardial ischemia and intractable ventricular arrhythmias developed. It was apparent that the significance of the RV-CACs was unpredictable, and they would have to be neutralized to make a $2 \mathrm{VR}$ reliably safe. Later, a patient with only an isolated RV-CAC was scheduled for repair on bypass, but inspection of the vessel indicated the communication could be ligated without decompressing the $\mathrm{RV}$, which opened the way for patients with PAIVS. Although many RVDs have been performed in the presence of RV-CACs, the procedure entails risk..$^{8,17,18}$ Because the determination that the circulation is RV dependent is not precise, SVRs remain common. ${ }^{4,5,6,19}$ We found the RV-CACs in the infants with PAIVS could be ligated without bypass, and with the possibility of a significant steal removed, RVD could be safely carried out. ${ }^{12}$ This approach was later confirmed. $^{25}$

A commonly held opinion is that net growth, especially of the TV, does not occur. Nevertheless, because hypoplasia is a developmental rather than a primarily genetic defect, net growth should be possible, as our longer-term analysis of TV growth has confirmed. Effective relief of the RV pressures and flow across the TV are necessary to induce growth of the hypoplastic ventricle. ${ }^{13}$ Although a detailed analysis of $\mathrm{RV}$ and RV growth in patients with PAIVS is beyond the scope of this study, our results with this approach demonstrate that even small TVs will catch up if the RVD is effective. For some of these patients, RV-CAC ligation will allow a 2 VR to be pursued.

\section{Conclusions}

This is the first series to demonstrate that RV-CACs can be reliably ligated off bypass and in these cases, it did not produce myocardial injury. Temporary ligation allowed the reversible assessment of the adequacy of antegrade CA flow when the connection was interrupted. In this series, the stenoses were not functionally significant and the ligations were made permanent. With the RV-CACs ligated, RVD can be carried out to maximize the potential for 2VRs. Even if the end point is an SVR, the long-term outlook should be improved.

The authors acknowledge the expert assistance of Brian Harvey, Linda King, and Jeanne Traaseth in the article preparation.

\section{References}

1. Bull C, de Leval MR, Mercanti C, Macartney FJ, Anderson RH. Pulmonary atresia and intact ventricular septum: a revised classification. $\mathrm{Circu}$ lation. 1982;66:266-72.

2. Kouchoukos NT, Blackstone EH, Doty DB, Hanley FL, Karp RB. Pulmonary atresia and intact ventricular septum. In: Kirklin/Barratt-Boyes Cardiac Surgery. 3rd ed., Vol. 2. Philadelphia: Churchill Livingstone; 2003:1095-1108.

3. Hanley FL, Sade RM, Blackstone EH, Kirklin JW, Freedom RM, Nanda NC. Outcomes in neonatal pulmonary atresia with intact ventricular septum. J Thorac Cardiovasc Surg. 1994;107:359-66.

4. Ashburn DA, Blackstone EH, Wells WJ, Jonas RA, Pigula FA, Manning PB, et al. Determinants of mortality and type of repair in neonates with pulmonary atresia and intact ventricular septum. $J$ Thorac Cardiovasc Surg. 2004;172:1000-8.

5. Freedom RM, Anderson RH, Perrin D. The significance of ventriculocoronary arterial connections in the setting of pulmonary atresia with an intact ventricular septum. Cardiol Young. 2005;15:447-68.

6. Jahangiri M, Zurakowski D, Bichell D, Mayer JE, del Nido PH, Jonas RA. Improved results with selective management in pulmonary 
atresia with intact ventricular septum. J Thorac Cardiovasc Surg. 1999; 118:1046-52.

7. Odim J, Laks H, Plunkett MD, Tung TC. Successful management of patients with pulmonary atresia with intact ventricular septum using a three tier grading system for right ventricular hypoplasia. Ann Thorac Surg. 2006;81:678-84.

8. Giglia TM, Mandell VS, Connor AR, Mayer JE, Lock JE. Diagnosis and management of right ventricle-dependent coronary circulation in pulmonary atresia with intact ventricular septum. Circulation. 1992;86: 1516-28.

9. Guleserian KJ, Armsby LB, Thiagarajan RR, del Nido PJ, Mayer JE. Natural history of pulmonary atresia with intact ventricular septum and right-ventricle-dependent coronary circulation managed by the single-ventricle approach. Ann Thorac Surg. 2006;81:2250-8.

10. Gittenberger-de Groot AC, Sauer U, Bindl L, Babic R, Essed CE, Buhlmeyer K. Competition of coronary arteries and ventriculo-coronary arterial communications in pulmonary atresia with intact ventricular septum. Int J Cardiol. 1988;18:243-58.

11. Calder AL, Co EE, Sage MD. Coronary arterial abnormalities in pulmonary atresia with intact ventricular septum. Am J Cardiol. 1987;59:436-42.

12. Steinberger J, Berry JM, Bass JL, Foker JE, Braunlin EA, Krabill KA, et al. Results of a right ventricular outflow patch for pulmonary atresia with intact ventricular septum. Circulation. 1992;86(5 suppl II):67-75.

13. Foker JE, Berry J, Steinberger J. Ventricular growth stimulation to achieve two-ventricle repair in unbalanced common atrioventricular canal. Prog Pediatr Cardiol. 1999;10:173-86.

14. Salvin JW, McElhinney DB, Colan SD, Gauvreau K, del Nido PJ, Jenkins KJ, et al. Fetal tricuspid valve size and growth as predictors of outcome in pulmonary atresia with intact ventricular septum. Pediatrics. 2006;118:415-20.

15. Gittenberger-de Groot AC, Tennstedt C, Chaoui R, Lie-Venema H, Sauer U, Poelmann RE. Ventriculo coronary arterial communications (VCAC) and myocardial sinusoids in hearts with pulmonary atresia with intact ventricular septum: two different diseases. Prog Pediatr Cardiol. 2001;13:157-64.
16. Gittenberger-de Groot AC, Eralp I, Lie-Venema H, Bartelings MM, Poelmann RE. Development of the coronary vasculature and its implications for coronary abnormalities in general and specifically in pulmonary atresia without ventricular septal defect. Acta Pediatr Suppl. 2004;446: 13-9.

17. Giglia TM, Jenkins KJ, Matitiau A, Mandell VS, Sanders SP, Mayer JE, et al. Influence of right heart size on outcome in pulmonary atresia with intact ventricular septum. Circulation. 1993;88:2248-56.

18. Gentles TL, Colan SE, Giglia RM, Mandell VS, Mayer JE Jr, Sanders SP. Right ventricular decompression and left ventricular function in pulmonary atresia with intact ventricular septum. The influence of less extensive coronary anomalies. Circulation. 1993;88: II183-8.

19. Rychik J, Levy H, Gaynor JW, DeCampli WM, Spray TL. Outcome after operations for pulmonary atresia with intact ventricular septum. Cardiovasc Surg. 1998;116:924-31.

20. Hausdorf G, Gravinghoff L, Keck EW. Effects of persisting myocardial sinusoids on left ventricular performance in pulmonary atresia with intact ventricular septum. Eur Heart J. 1987;8:291-6.

21. Sholler GF, Colan SD, Sanders SP. Effect of isolated right ventricular outflow obstruction on left ventricular function in infants. Am J Cardiol. 1988;62:778-84.

22. Fenton KN, Pigula FA, Gandhi SK, Russo L, Duncan KF. Interim mortality in pulmonary atresia with intact ventricular septum. Ann Thorac Surg. 2004;78:1994-8.

23. Tanoue Y, Kado H, Maeda T, Shiokawa Y, Fusazaki N, Ishikawa S. Left ventricular performance of pulmonary atresia with intact ventricular septum after right heart bypass surgery. J Thorac Cardiovasc Surg. 2004; 128:710-7.

24. Foker JE, Braunlin EA, St Cyr JA, Hunter D, Molina JE, Moller JH, et al. Management of pulmonary atresia with intact ventricular septum. $J$ Thorac Cardiovasc Surg. 1986;92:706-15.

25. Hisagi M, Suzuki Y, Nakayama S. Biventricular repair for pulmonary atresia with intact ventricular septum associated with sinusoidal communications. Jpn J Thorac Cardiovasc Surg. 2003;51:25-8. 